\title{
Transuranic and fission product determination in soils and sediments from Alpin Wetland, Boréon (France)
}

\author{
H. Michel, G. Barci-Funel and G. Ardisson \\ Laboratoire de Radiochimie et Radioécologie, Universite de Nice-Sophia Antipolis, \\ 28 avenue Valrose, 06108 Nice, France
}

\begin{abstract}
The study of an Alpine Wetland presented in this study can bring interesting answers to the problems of the environment management. The determination of the radionuclides in soils and sediments has allowed not only to establish the history of depositions and consequently the origin of the radionuclides, but also to evaluate the various transfers, which took place. The studied elements are plutonium 238, 239-240, americium 241, caesium 134, 137 and strontium 90 . The detailed vertical study of sediment core shows the accumulation mode and gives infomation on the sectimentation rate of the small lake. The study of isotopic ratios allows understanding the origin and the environmental behaviour of the elements. Soril core inventory shows the activity on this region. The evolution of the activity versus the altitude is made.
\end{abstract}

\section{INTRODUCTION}

The nuclear tests carried out in the atmosphere in the Sixties, the accidents and in particular that at the power station of Chernobyl in 1986, were at the origin of significant dispersion of transuranic elements and fission products.

Samples of soil and sediment from a small lake were collected in the Vésubie valley forest in the South East of France and analysed by gamma, alpha and beta spectrometry.

The radionuclides studied are ${ }^{734},{ }^{137} \mathrm{Cs},{ }^{90} \mathrm{Sr},{ }^{241} \mathrm{Am},{ }^{238,}{ }^{239-240} \mathrm{Pu}$. A radiochemical separation is presented for the determination of the elements. This procedure is tested with reference materials given by the I.A.E.A.

The detailed vertical study of sediment core shows the accumulation mode and gives information on the sedimentation rate of the small lake. The study of isotopic ratios allows understanding the origin and the environmental behaviour of the elements. Soil core inventory shows the activity on this region. The evolution of the activity versus the altitude is made.

\section{SAMPLING}

The soil and sediment samples come from "le parc du Mercantour, le Boréon". The site is an alpine wetland at $30 \mathrm{~km}$ of Nice $\left(44^{\circ} 07 \mathrm{~N}, 7^{\circ} 20 \mathrm{E}\right)$ in the South of France.

Soils were sampled with a rigid frame of known area $\left(20 \times 20 \mathrm{~cm}^{2}\right)$ driven into the soil. Samples were dried in an oven at $100^{\circ} \mathrm{C}$ for 1.2 days, then ground to make a homogeneous powder. For soils, the large particles (pebbles) were discarded with a sieve. 6 soil samples (A, A', B, B', C, $C^{\prime}$ ) have been analysed in $\mathrm{Pu}, \mathrm{Am}, \mathrm{Cs}$ and $\mathrm{Sr}$ to compare the deposition of these elements. Their characteristics are given in the table 1 . The samples $\left(A, A^{\prime}\right)\left(B, B^{\prime}\right)$ and $\left(C, C^{\prime}\right)$ were sampling in three locations. The sample $\left(S, S^{\prime}\right)$ are coming from the same site but the depth for the sample $S=A, B$ and $C$ is $2.5 \mathrm{~cm}$ and $5 \mathrm{~cm}$ for the sample $S^{\prime}=A^{\prime}, B^{\prime}$ and $C^{\prime}$. 10 others soil samples have been analysed only in Cs. These samples have been collected at different altitudes to study the influence of this factor.

Sediment core was collected in the small lake "Gardes Chasse" using a $6 \mathrm{~cm}$ diameter corer. The core was extruded vertically. The wet sediment samples were dried at $100^{\circ} \mathrm{C}$ to determine the water content. 
Table 1: Characteristics of the studied soil samples.

\begin{tabular}{|c|c|c|c|l|}
\hline Sample & Site & Aititude & Depth & Collection date \\
\hline A & Gardes-chasse & $1760 \mathrm{~m}$ & $0-2.5 \mathrm{~cm}$ & May 2000 \\
\hline $\mathbf{A}^{\prime}$ & Gardes-chasse & $1760 \mathrm{~m}$ & $0-5 \mathrm{~cm}$ & May 2000 \\
\hline B & Pont de Peïrastrèche & $1850 \mathrm{~m}$ & $0-2.5 \mathrm{~cm}$ & May 2000 \\
\hline B $^{\prime}$ & Pont de Peïrastrèche & $1850 \mathrm{~m}$ & $0-5 \mathrm{~cm}$ & May 2000 \\
\hline C & Lac de Trecoulpas & $2100 \mathrm{~m}$ & $0-2.5 \mathrm{~cm}$ & May 2000 \\
\hline C $^{\prime}$ & Lac de Trecoulpas & $2100 \mathrm{~m}$ & $0-5 \mathrm{~cm}$ & May 2000 \\
\hline
\end{tabular}

\section{EXPERIMENTAL PROCEDURE}

\subsection{Gamma-spectrometry measurements}

${ }^{137}$ Cs measurements were carried out by standard $\psi$-spectrometry using methods described in (1-3). The samples were packed into plastic containers and counted on a coaxial HPGe detector (EG\&G ORTEC) of $17 \%$ relative efficiency with an energy resolution FWHM (Full Width at Half Maximum) of $1.9 \mathrm{keV}$ at $1.33 \mathrm{MeV}$. The efficiency of detector was determined using standard sources with the same geometrical configuration as the samples being measured. Placing the detector inside a $5 \mathrm{~cm}$ thick lead castle with a 2 mm thick copper lining reduced background radiation. The spectra were collected using a multi-channel buffer analyzer (Spectrum Master ORTEC 919).

\subsection{Alpha and Beta spectrometry measurements}

Typical amounts of $30 \mathrm{~g}$ were ashed in porcelain dishes during 24 hours in a large electric muffle furnace with a gradual heating program up to $600^{\circ} \mathrm{C}$. The samples are mixed with $1 \mathrm{M} \mathrm{HNO}$ to produce slurry. 10 $\mathrm{mg}$ of strontium carrier and spikes of ${ }^{243} \mathrm{Am}(100 \mu \mathrm{l}$ of $0.128 \pm 0.013 \mathrm{~Bq} / \mathrm{ml})$ and ${ }^{242} \mathrm{Pu}(100 \mu \mathrm{lof}$ $0.1459 \pm 0.0067 \mathrm{~Bq} / \mathrm{ml}$ ) tracers are added. Spiked slurries are stirred, leached twice with $8 \mathrm{M} \mathrm{HNO}_{3}$ and some $\mathrm{H}_{2} \mathrm{O}_{2}$ drops.

The supernate is evaporated to dryness and $1 \mathrm{M} \mathrm{HNO}_{3}$ solutions are added together with $\mathrm{Ca}$ and oxalic acid. Some drops of $25 \%$ hydrazinium hydroxide are added to adjust the oxidation state of Pu to III. The $\mathrm{pH}$ of the solution is adjusted to 5.5-6.0 with ammonia so that Pu, Am and Sr are co-precipitated. Under these conditions in many cases, most of the Fe remains in solution in the form of oxalate complexes. The precipitate is centrifuged and washed with distilled water. The oxalate precipitate is destroyed by evaporation with $65 \% \mathrm{HNO}_{3}$.

After destruction of the oxalate by cooking with $65 \% \mathrm{HNO}_{3}$, the solution is diluted with deionised water. $20 \mathrm{mg}$ of $\mathrm{Fe}^{3+}$ are added and the $\mathrm{pH}$ of the solution adjusted to $8-9$ with ammonia. Strontium stays in solution (A) and $\mathrm{Pu}$ and $\mathrm{Am}$ are co-precipitated $\left(\mathrm{Fe}(\mathrm{OH})_{3}\right)(\mathrm{B})$. The precipitate is dissolved in $65 \%$ $\mathrm{HNO}_{3}$. The solution is evaporated to dryness and taken up in $1 \mathrm{MHNO}$.

\subsubsection{A-Separation of strontium with Sr-Spec}

The $\mathrm{pH}$ of the supernate of the $\mathrm{Fe}(\mathrm{OH})_{3}$ co-precipitation is adjusted to 8 . Some $2.5 \mathrm{M} \mathrm{Na} \mathrm{CO}_{3}$ solutions are added until no precipitation is observed. The precipitate which contains $\mathrm{Sr}$ is dissolved in $65 \% \mathrm{HNO}_{3}$, evaporated to dryness and taken up in $3 \mathrm{M} \mathrm{HNO}_{3}$. This precipitation allows eliminating $\mathrm{K}$ and $\mathrm{Na}$. 
Columns are prepared from Sr-Spec ${ }^{\$}$ supported crown ether. Columns are conditioned with $3 \mathrm{M}$ $\mathrm{HNO}_{3}$. Sample solutions are loaded to the column, and then the columns are washed with $3 \mathrm{M} \mathrm{HNO}$ to remove most of the alkaline earth metal interferences (Ca). Strontium is stripped with distilled water. The Strontium solution is evaporated to dryness and taken up with $\mathrm{IM} \mathrm{HNO}_{3}$.

Oxalic acid is added to the solution. Strontium oxalate is precipitated from alkaline solution by adding $\mathrm{NH}_{3}$ (pH 8-9). The precipitate is filtered through pre-weighted filter paper. The chemical recovery for strontium is determined by gravimetry. Samples are dissolved in $1 \mathrm{ml} 1 \mathrm{M} \mathrm{HNO}$ and mixed with 15 ml Aquasaf 300 Plus scintillation cocktail. Strontium- 90 is analyzed by liquid scintillation counting.

\subsubsection{B-Plutonium and americium separation}

In the $1 \mathrm{M} \mathrm{HNO}_{3}$ solution, which contains the $\mathrm{Pu}$ and $\mathrm{Am}, 25 \%$ hydrazinium hydroxide are added to adjust the oxidation state of $\mathrm{Pu}$ to III. Then, $65 \% \mathrm{HNO}_{3}$ are added and the solution heated to destroy the excess of hydrazinium hydroxide. Samples are cooled and sodium nitrite is added to ensure conversion of $\mathrm{Pu}$ (III) to $\mathrm{Pu}$ (IV). $65 \% \mathrm{HINO}_{3}$ are added to the solution to adjust the concentration of the solution to about $8 \mathrm{M}$.

Columns are prepared from Bio Rad $A G^{3} 1-X 8$ (mesh 100-200) resin in the chloride form. Columns are conditioned with $\mathbf{8} \mathrm{M} \mathrm{HNO}_{3}$. Sample solutions are loaded into the column followed by washing with $8 \mathrm{M} \mathrm{HNO}_{3}$. The combined effluent is used for the analysis of Am. Columns are washed with $10 \mathrm{M} \mathrm{HCl}$ to desorb Th. Finally, Pu is stripped with $0.1 \mathrm{M} \mathrm{NH} 4-10 \mathrm{M} \mathrm{HCl}$ solution. It's also possible to elute neptunium at this step with 4.5M HCl-0. IM HF (4). The Pu strip solution is evaporated to dryness after addition of $5 \% \mathrm{NaHSO}_{4}$.

The solution is electroplated, in a classical $\mathrm{H}_{2} \mathrm{SO}_{4} / \mathrm{NH}_{3}$ medium, on a stainless steel disc during 1 hour with a current of $1 \mathrm{~A}$.

The combined effluent from the anion exchange column is evaporated to dryness. An oxalic acid precipitation is made to eliminate the iron. After dissolution of the precipitate, the solution is converted in chloride with $10 \mathrm{M} \mathrm{HCl}$.

Mixed anion-cation exchange columns are prepared from Bio Rad AG(P) 1- $\times 8$ (mesh 100-200) resin in the chloride form and Bio Rad $A G \otimes 50 w-\times 8$ (mesh 100-200) resin in $\mathrm{H}+$ form. Column is conditioned with $10 \mathrm{M} \mathrm{HCl}$. Sample solutions are ioaded into the column followed by washing with $10 \mathrm{M}$ $\mathrm{HCl}$. The two resins retain the traces of $\mathrm{Th}, \mathrm{Fe}$, Po and $\mathrm{Pu}$. The solution is evaporated to dryness and taken up in $65 \% \mathrm{HNO}_{3}$, then in $2 \mathrm{M} \mathrm{HNO}_{3}$.

TRU-Spec $\otimes$ resin column is prepared. Columns are conditioned with $2 \mathrm{M} \mathrm{HNO}_{3}$. Samples are loaded to the column followed by washing with $2 \mathrm{M} \mathrm{HNO}_{3}$. The column is washed with $9 \mathrm{M} \mathrm{HCl}+25 \%$ $\mathrm{NaNO}_{2}$ and 9M HCl. Finally Am together with the lanthanides are stripped with $4 \mathrm{M} \mathrm{HCl}$ solution. The traces of Th and $U$ that might be present remain on the column. This step could be done by liquid-liquid extraction with DDCP or HDEHP (5-7).

The $4 \mathrm{M} \mathrm{HCl}$ solution is evaporated to dryness and converted to nitrate with $65 \% \mathrm{HNO}_{3}(3 \times 1 \mathrm{ml})$. The residue is taken up with $1 \mathrm{M} \mathrm{HNO}_{3}-93 \% \mathrm{CH}_{3} \mathrm{OH}$. Columns are prepared from Bio $\mathrm{Rad} \mathrm{AG \otimes} 1 \times 4$ (mesh 100-200) resin. Columns are conditioned with $1 \mathrm{M} \mathrm{HNO}_{3}-93 \%$ methanol. Samples are loaded onto the columns followed by washing with $1 \mathrm{M} \mathrm{HNO}_{3}-93 \%$ methanol. Columns are washed with $0.1 \mathrm{M} \mathrm{HCl}-$ $0.5 \mathrm{M} \mathrm{NH} 4 \mathrm{SCN}-80 \%$ methanol solution to remove the lanthanides. A wash with $1 \% \mathrm{HNO}_{3}-93 \%$ methanol is performed. Americium is stripped with $1.5 \mathrm{M} \mathrm{HCl}-86 \%$ methanol solution.

The Am strip solution is evaporated to dryness and electroplate on a stainless steel disc. The solution is electroplated during 1 hour with a current of $1 \mathrm{~A}$. 


\subsubsection{Beta-scintillation counting}

The determination of the activity concentration of ${ }^{90} \mathrm{Sr}$ is performed using the double energetic windows method. The first energetic window (window A) includes the entire ${ }^{90} \mathrm{Sr}$ spectrum and the low energy region of ${ }^{90} \mathrm{Y}$ spectrum. The window $\mathrm{B}$ includes the high-energy region of ${ }^{90} \mathrm{Y}$ spectrum. Strontium-90 activity is determined by subtracting the contribution of ${ }^{90} \mathrm{Y}$ in region $\mathrm{A}$ from total counting rate in this region. The detection is made with liquid scintillation detector Packard $2000 \mathrm{CA}$

\subsubsection{Alpha-spectrometry}

The disintegration rate of the analyte activities in each sample is calculated on the basis of the known tracer activities added to the sample. The ratio of the $\alpha$-spectral peak areas after corrections for background, tailing and reagent blank is taken to be equal to the ratio of the disintegration rates.

$\alpha$ spectra were measured with Dual Alpha Spectrometers EG\&G Ortec 576A equipped with boron implanted silicon detectors of active area: $450 \mathrm{~mm}^{2}$ and alpha resolution (FWHM) $20 \mathrm{keV}$ at $5.47 \mathrm{MeV}$. Pulses were analysed with a multichannel buffer analyser (spectrum master Ortec 919).

\section{RESULTS AND DISCUSSION}

To be applied to unknown samples, the procedure should be tested with reference materials. IAEA 375 and Soil 6 are two soils distributed by the I.A.E.A., M.E.L. IAEA 375 is collected in Chernobyl area in 1990 and soil 6 is collected in Austria in 1983 at $1100 \mathrm{~m}$ altitudes.

The activity results and the recommended values for the two reference materials are shown in Table 2. The two reference materials have been chosen for their good $\mathrm{Sr}$ recommended valucs. The activity concentrations of ${ }^{238,239-240} \mathrm{Pu}$ and ${ }^{90} \mathrm{Sr}$ are all within the confidence interval of the information value. An abnormally high value was obtained for americium in IAEA 375, but Moreno et al (8) give the same result.

Table 2: Activities obtained with our procedure and LAEA recommended values

a) at collection date: $12 / 31 / 91$

b) at collection date:01/30/83

\begin{tabular}{|c|c|c|c|c|}
\hline-1 & \multicolumn{2}{|c|}{ IAE $\mathbf{A 3 7 5}$} & \multicolumn{2}{|r|}{ Soll 6 } \\
\hline & $\begin{array}{c}\text { Activity obtained } \\
\mathrm{B} \mathbf{k} \mathbf{k g}\end{array}$ & $\begin{array}{l}\text { Recommended values } \\
\mathrm{B} q \mathrm{~kg}\end{array}$ & $\begin{array}{l}\text { Activity } \\
\text { obtained } \mathrm{Bg} / \mathrm{kg}\end{array}$ & $\begin{array}{c}\text { Recommended values } \\
\mathrm{B} / \mathrm{kg}\end{array}$ \\
\hline${ }^{239-200} \mathbf{P u}$ & $0.34(0.02)$ & $0.3(0.26-0.34)$ & $1.04(0.06)$ & $1.04(0.96-1.11)$ \\
\hline${ }^{238} \mathbf{P u}$ & $0.081(0.005)$ & $0.071(0.056-0.085)$ & $0.026(0.003)$ & no info \\
\hline${ }^{241} \mathrm{Am}$ & $0.23(0.01)$ & $0.13(0.11-0.15)$ & $0.39(0.02)$ & no info \\
\hline${ }^{90} \mathrm{Sr}$ & $103(7)^{21}$ & $108(101-114)^{2}$ & $26(2)^{b)}$ & $30.34(24.20-31.67)^{b)}$ \\
\hline${ }^{137} \mathrm{Cs}$ & $5320(260)^{21}$ & $5280(5200-5360)^{21}$ & $55(4)$ b) & $53.7(51.5-58.0)^{b)}$ \\
\hline
\end{tabular}

The results for the Boréon soil samples are given in Table 3. The activity for the three locations is not the same even if the fallout could be considered as homogenous. For the sample labelled ( $A, A^{\prime}$ ) the activity for the $A$ is less important than for the $A^{\prime}$. A depth migration of the radionuclides occurred for this sample. But for the sample (B, B') and (C, C) the activity in the sample $0-2.5 \mathrm{~cm}$ is higher than in the sample $0-5 \mathrm{~cm}$. Most of the activity is in the top layer and the migration should be very slight for these two locations. These three locations show that the accumulation and the migration of the radionuclide 
fallout are depending of a lot of parameters as the chemical soil composition. the altitude and the vegetation. This search should be investigated and described elsewhere.

Table 3: Activities cbtained for the soil samples of Bor $60 n(B q / k g)$

a) At collection date: $1805 / 00$

\begin{tabular}{|c|c|c|c|c|c|c|}
\hline Sample & $\mathbf{A}$ & $\mathbf{A}^{\prime}$ & $\mathbf{B}$ & B' & $\mathbf{C}$ & C' \\
\hline${ }^{234.200} \mathrm{Pu}$ & $1.24(0.07)$ & $5.8(0.3)$ & $2.9(0.2)$ & $0.44(0.03)$ & $5.1(0.3)$ & $4.1(0.2)$ \\
\hline${ }^{206} \mathrm{Pu}$ & $0.038(0.003)$ & $0.18(0.02)$ & $0.093(0.006)$ & $0.014(0.001)$ & $0.17(0.01)$ & $0.13(0.01)$ \\
\hline${ }^{241} \mathrm{Am}$ & $0.44(0.03)$ & $2.2(0.2)$ & $1.05(0.07)$ & $0.17(0.01)$ & $1.9(0.1)$ & $1.6(0.1)$ \\
\hline${ }^{n} \mathrm{Sr}{ }^{\circ}$ & $21(2)$ & $33(2)$ & $49(3)$ & $10.3(0.9)$ & $37(2)$ & $81(5)$ \\
\hline${ }^{137} \mathrm{Cs}^{\text {*) }}$ & $420(30)$ & $687(40)$ & $818(50)$ & $24(3)$ & $891(60)$ & $753(45)$ \\
\hline
\end{tabular}

The Table 4 gives the usual isotopic ratios. For all the samples ${ }^{238} \mathrm{Pu} /{ }^{239-240} \mathrm{Pu}$ and ${ }^{241} \mathrm{Am} /{ }^{239-240} \mathrm{Pu}$ isotopic ratios are nearly the same and the average values are respectively 0.031 and 0.37 . The accumulation and migration of plutonium and americium is the same for these kinds of soils. The values of these two ratios are representative of the atmospheric nuclear test fallout and no Chernobyl contribution takes place for plutonium and americium for these areas. The calculated isotopic ratios, ${ }^{137} \mathrm{Cs} /{ }^{239-240} \mathrm{Pu}$ and ${ }^{60} \mathrm{Sr} /{ }^{239-240} \mathrm{Pu}$, are different for all the samples and for the three sites. The behaviour of caesium and strontium in soil is different from that of plutonium. The ratio ${ }^{90} \mathrm{Sr} /{ }^{137} \mathrm{Cs}$ shows that strontium and caesium accumulation in the soil is not the same. The typical ${ }^{90} \mathrm{Sr} /{ }^{137} \mathrm{Cs}$ isotopic ratio is estimated to 0.02 for the Chernobyl accident and 0.625 for the global fallout. For these soils the value is higher to 0.02 and could attempt 0.43 for the sample B: So, the nuclear test fallout and Chernobyl accident fallout are mixed in the five first centimetre of soils, but the contribution is difficult to estimate because the strontium and caesium behaviour is different.

Table 4: Isotopic ratios

\begin{tabular}{|c|c|c|c|c|c|c|}
\hline Sample & $\mathbf{A}$ & $\mathbf{A}^{\prime}$ & B & B' & $\mathbf{C}$ & $\mathbf{C}^{\prime}$ \\
\hline${ }^{208} \mathrm{Pu} /{ }^{239-200} \mathrm{Pu}$ & $\begin{array}{c}0.030 \\
(0.003)\end{array}$ & $\begin{array}{c}0.031 \\
(0.004)\end{array}$ & $\begin{array}{c}0.032 \\
(0.003)\end{array}$ & $\begin{array}{c}0.031 \\
(0.003)\end{array}$ & $\begin{array}{c}0.033 \\
(0.003)\end{array}$ & $\begin{array}{c}0.032 \\
(0.003)\end{array}$ \\
\hline${ }^{241} \mathrm{Am} /{ }^{239-2400} \mathrm{Pu}$ & $0.35(0.03)$ & $0.38(0.04)$ & $0.36(0.03)$ & $0.38(0.03)$ & $0.36(0.03)$ & $0.38(0.03)$ \\
\hline${ }^{137} \mathrm{Cs}^{239-240} \mathrm{Pu}$ & $339(31)$ & $118(9)$ & $282(26)$ & $54(8)$ & $175(16)$ & $184(14)$ \\
\hline${ }^{90} \mathrm{~S} r{ }^{230.210} \mathrm{Pu}$ & $17(2)$ & $5.7(0.5)$ & $17(2)$ & $23(3)$ & $7.3(0.6)$ & $20(2)$ \\
\hline${ }^{6} \mathrm{Sr} /{ }^{137} \mathrm{Cs}$ & $\begin{array}{c}0.050 \\
(0.006)\end{array}$ & $\begin{array}{c}0.048 \\
(0.004)\end{array}$ & $\begin{array}{c}0.059 \\
(0.005)\end{array}$ & $0.43(0.07)$ & $\begin{array}{c}0.041 \\
(0.004)\end{array}$ & $0.11(0.01)$ \\
\hline
\end{tabular}

The table 5 shows the $137 \mathrm{Cs}$ sediment activity profile in the small lake at the Gardes Chasse site. Two maximum radioactivities appear clearly: one at the slice $3-5 \mathrm{~cm}$ and another at the slice $13-15 \mathrm{~cm}$. Only the nuclear weapon test fallout and the Chernobyl accident fallout have contaminated this mountain area. The depth $14 \mathrm{~cm}$ correspond to the date 1963 and the depth $4 \mathrm{~cm}$ to 1986 . As the surface layer $(0 \mathrm{~cm})$ corresponds to the date 2000 , it's possible to estimate mean sedimentation rates from these two events. For the period 1986-2000, the sedimentation rate obtains is $2.9 \mathrm{~mm} / \mathrm{y}$, for $1963-2000$, the result is 3.8 $\mathrm{mm} / \mathrm{y}$ and for $1963-1986$, the value is $4.3 \mathrm{~mm} / \mathrm{y}$. With other sediment cores it will be interesting to comfort these values and with soil cores to understand the soil erosion mechanism which should be one of the reasons of the sedimentation rate variations. 
Table 5: ${ }^{177} \mathrm{Cs}$ sediment activity profile

\begin{tabular}{|c|c|c|}
\hline Slice cm & Depth cm & $\begin{array}{c}\text { 137Cs activity Bq/kg } \\
(05 / 18 / 00)\end{array}$ \\
\hline $0-3$ & 1.5 & $120(7)$ \\
\hline $3-5$ & 4 & $260(13)$ \\
\hline $5-8$ & 6.5 & $180(9)$ \\
\hline $8-13$ & 10.5 & $36(2)$ \\
\hline $13-15$ & 14 & $190(10)$ \\
\hline $15-17$ & 16 & $130(7)$ \\
\hline $17-22$ & 19.5 & $50(3)$ \\
\hline
\end{tabular}

Figure 1 present the 134 and 137 caesium activity concentration as a function of the altitude. These activities are mainly due to Chernobyl fallout because it's surface soil samples. The curves show maxima near to $1700 \mathrm{~m}$. Higher rainfalls in this region may explain this; moreover, at the highest altitudes, soil

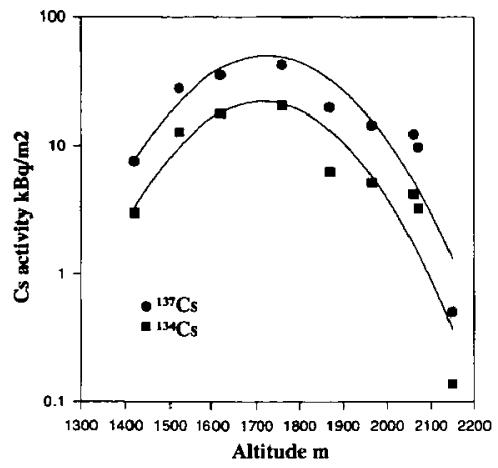

Figure 1: 137 and 134 caesium activity concentration as a function of altitude in the Boréon valley

was still covered by snow at the end of April and the melting snow could have carried down an amount of the fallout. This altitude corresponds also to a more dense forest.

The greater deposition of radionuclides in coniferous forests was already observed $(9,10)$. This increase is due to the interception of radionuclides by the canopy and to the contribution of the litter fall to the activity deposited on the forest floor. 


\section{References}

[1] Barci-Funel G., Dalmasso J., Ardisson G., Sci. Tot. Environ. 70, (1988) 373.

[2] Barci-Funel G., Dalmasso J., Ardisson G, J. Radioanal. Nucl. Chem. 156, (1992) 83.

[3] Holm E., Ballestra S., Lopez J.J., Bulos A., Whitehead N.E., Barci-Funel G., Ardisson G., J. Radioanal. Nucl. Chem, 177 (1994) 51.

[4] Michel H., Barci-Funel G., Dalmasso J., Ardisson, J. Radioanal. Nucl. Chem, 240 (1999) 467.

[5] Measurement of radionuclides in Food and the Environment (IAEA Technical Reports Series N ${ }^{\circ} 295$, Vienna 1989).

[6] Michel H., Gasparro J., Barci-Funel G., Ardisson G., Talanta 48, (1999) 821.

[7] Ballestra S., Fukai R., Talanta 30 (1983) 45.

[8] Moreno J., Vajda N., Danesi P.R., Larosa J.J., Zeiller E., Sinojmeri M., J. Radioanal. Nucl. Chem. 226, (1997) 279.

[9] Bunzl K., Kracke W., J. Environ. Radioactivity, 8 (1988) 1

[10] Bunzl K., Schimmack W., Kreutzer K., Schierl R., Sc. Tot. Environm. 78 (1989) 77. 